ISSN: 1808-8759

\title{
SELO DE COMBUSTÍVEL SOCIAL - DESAFIOS E OPORTUNIDADES
}

\author{
Sérgio Gonçalves Dutra ${ }^{1} \&$ Osmar De Carvalho Bueno
}

\begin{abstract}
RESUMO: A instituição, em 2004, do Programa Nacional de Produção e Uso do Biodiesel - PNPB, pelo Governo Federal, iniciou um debate sobre a efetividade dos mecanismos propostos para fortalecer a agricultura familiar, por meio do Selo Combustível Social que passou a ser concedido pelo Ministério do Desenvolvimento Agrário - MDA às empresas produtoras de biodiesel, que atendessem determinados critérios, que em troca passaram a ter benefícios na comercialização de biodiesel. Em 2009, a Cooperativa dos Agricultores Familiares da Região Centro Paulista (COOPERFASC) decidiu produzir soja, incentivada pelo Selo Combustível Social, nos assentamentos rurais: Bela Vista do Chibarro e Fazenda Monte Alegre. Essa iniciativa foi objeto de um estudo de caso, levando em conta os riscos e oportunidades decorrentes desses plantios, na região centro paulista, nas safras 2010/2011, 2012/2012 e 2012/2013. Apesar da evolução dos sistemas de produção em uso pelos agricultores familiares, no período acompanhado e do aperfeiçoamento dos instrumentos regulatórios do Selo Combustível Social, pelo MDA, a heterogeneidade do ambiente produtivo e as condições climáticas ocorridas, nas referidas safras, levaram os dirigentes e associados da Cooperfasc a interromper a produção de soja para biodiesel, optando por outras atividades, a partir da safra 2013/2014.
\end{abstract}

PALAVRAS-CHAVE: biodiesel, selo combustível, agricultura familiar, assentamentos rurais

\section{SEAL OF SOCIAL FUEL - CHALLENGES AND OPPORTUNITIES}

\begin{abstract}
The implementation of the National Program for Production and Use of Biodiesel - PNPB, in 2004 by the Federal Government, influenced a debate on the effectiveness of the proposed mechanisms to strengthen family agriculture, through the Social Fuel Seal. This seal is granted by the Ministry of Agrarian Development - MDA to biodiesel companies that production meets certain criteria, which in turn came to have benefits in the biodiesel marketing. In 2009, the Cooperative of Family Farmers in the Sao Paulo Central Region (COOPERFASC) decided to produce soybeans, encouraged by the Social Fuel Seal, in the rural settlements: Bela Vista do Chibarro and Fazenda Monte Alegre. This initiative was the subject of a case of study, taking into account the risks and opportunities arising from these plantations in Sao Paulo Central Region, in the harvest periods of 2010/2011, 2012/2012, and 2012/2013. Despite the evolution of production systems in use by farmers, accompanied by the improvement of the regulatory instruments of the Social Fuel Seal by MDA, the heterogeneity of the productive environment and climatic conditions occurring in the analyzed seasons led the leaders and associates Cooperfasc to interrupt the production of soybeans biodiesel, and opt for other activities, from the 2013/2014 harvest period.
\end{abstract}

KEYWORDS: biodiesel, fuel seal, family farming, rural settlements.

\footnotetext{
${ }^{1}$ Instituto Mato-grossense do Algodão. E-mail: sgdutra.sc@gmail.com

${ }^{2}$ Professor Livre Docente - Faculdade de Ciências Agronômicas da

Universidade Estadual Paulista "Júlio de Mesquita Filho" - Campus de

Botucatu - Botucatu/SP. E-mail: osmar@fca.unesp.br
} 


\section{INTRODUÇÃO}

No Brasil, até a década de 2000, a temática da agroenergia tinha como foco principal o setor sucroalcooleiro, com um acalorado debate sobre a sustentabilidade do mesmo.

A política de intervenção estatal no complexo canavieiro nacional sempre foi bastante questionada, sendo que, a partir dos anos 80, alterações na política e no ambiente institucional obrigaram as empresas a adotar estratégias diferenciadas das anteriores, buscando a competitividade nacional e internacional.

Essas mudanças propiciaram um aumento das atividades do setor e, após a crise do final dos anos 90, intensificouse a descentralização do processo produtivo, principalmente quanto ao carregamento e transporte da cana sem, contudo, um significativo incremento da produtividade agrícola, pois o aumento da produção sempre esteve mais associado à expansão da área de plantio do que ao aumento da produtividade (NOVACANA, 2014).

Naquela oportunidade Graziano da Silva (2000), estimaram que a reestruturação do sistema produtivo da cana-de-açúcar tenderia a eliminar de $30 \%$ a $40 \%$ da área total de cana plantada no Estado de São Paulo, atingindo, principalmente, os trabalhadores safristas e os pequenos e médios fornecedores, com um grande impacto sobre as economias dos chamados municípios canavieiros.

Nesse ambiente foi instituído, em 2004, o Programa Nacional de Produção e Uso do Biodiesel - PNPB, por parte do Governo Federal, como proposição de política pública para a agricultura familiar, de abrangência nacional, no âmbito das cadeias produtivas de agroenergia, a ser efetivada por meio do Selo Combustível Social.

O Selo Combustível Social foi apresentado como componente de identificação a ser concedido pelo Ministério do Desenvolvimento Agrário - MDA às empresas produtoras de biodiesel que, sob determinados critérios, viessem a promover a inclusão social e o desenvolvimento regional por meio da geração de emprego e renda para os agricultores familiares (BRASIL, 2014).

Segundo a ANP (2014) esse Selo passou a ser concedido às empresas produtoras de biodiesel, devidamente credenciados pelo MDA, que, em contrapartida, passaram a ter acesso, com exclusividade, ao principal lote do Leilão da Agência Nacional de Petróleo, Gás Natural e Biocombustíveis - ANP, no qual são adquiridos $80 \%$ do volume total de biodiesel comprado pelo Governo Federal, em cada Leilão.

Dentre os itens principais a serem cumpridos por parte das empresas produtoras de biodiesel para obtenção do Selo Combustível Social estão:
1) Adquirir, de agricultores familiares, matéria-prima para a produção de biodiesel em uma quantidade mínima, que varia conforme a região do país, definida pelo MDA;

2) Celebrar contratos com os agricultores familiares e suas organizações, negociados com a participação de uma entidade representativa dos agricultores familiares, especificando as condições comerciais que garantam renda e prazos compatíveis com a atividade; e

3) Assegurar assistência e capacitação técnica aos agricultores familiares.

Num primeiro momento o PNPB foi duramente criticado, pois se aventava a possibilidade de haver uma redução na produção de alimentos por parte dos agricultores familiares brasileiros.

Após um grande impulso inicial, nos primeiros 05 anos de vigência do Programa, onde a produção de biodiesel cresceu de forma acelerada, tem prevalecido um cenário de menor crescimento da produção de biodiesel no país, onde o último grande alento à consolidação do mesmo foi a resolução do Conselho Nacional de Política Energética (CNPE) estabelecendo o mínimo de 5\% de adição de biodiesel ao óleo diesel comercializado ao consumidor final, publicada no Diário Oficial da União (D.O.U.) de 26 de outubro de 2009.

A adição de 5\% de biodiesel ao óleo diesel, conhecida como B5, que estava prevista em lei para começar a vigorar em 2013, passou a ser obrigatório em todo o território nacional a partir de $1^{\circ}$ de janeiro de 2010 , contribuindo para a manutenção do crescimento da produção de biodiesel, num primeiro momento.

De acordo com os dados disponíveis no sitio da Agência Nacional do Petróleo, Gás Natural e Biocombustíveis ANP (2014) a partir de 2011, o ritmo de crescimento da produção de biodiesel começou a diminuir, sendo que em 2013 houve um pequeno incremento na produção de biodiesel, mas sem a mesma intensidade da evolução da produção observada de 2005 a 2010. Outro aspecto, bastante criticado, do PNPB é o fato de a principal matéria prima utilizada para a fabricação de biodiesel, passados mais de 09 anos de seu lançamento, continuar sendo a soja. Segundo o Portal Brasil (2014) o próprio MDA em seus informes tem demonstrado isso, afirmando que em 2013 a soja foi responsável por $96 \%$ da matéria prima ofertada pela agricultura familiar para a produção de biodiesel.

A soja, em função da conjuntura internacional, conforme dados apresentados pelo Instituto de Economia Agrícola - IEA (2014) teve preços ascendentes, nos últimos anos, o que favoreceu as empresas que já possuíam capacidade instalada para o esmagamento de soja, bem como mercado para colocação de farelo e óleo de soja.

Para essas empresas a produção de biodiesel, incentivada pelo PNPB, aumentou seu leque de opções, podendo 
destinar o óleo de soja que já produzia, tradicionalmente, tanto para o mercado alimentício, como para a fabricação de biodiesel.

Já as empresas de biodiesel que não tinham atuação anterior no complexo soja, sem contar com fornecedores regulares dessa matéria prima, nem possuem planta industrial para esmagamento de soja e extração de óleo, tem, em sua grande maioria, segundo D'Ercole (2014), enfrentado grandes dificuldades, muitas delas reduzindo a produção ou saindo da atividade.

Estudos econômicos, realizados junto a empresas produtoras de biodiesel, já apontavam, em 2010, para esse cenário, conforme apresentado por Sarmento (2010).

Quando do lançamento do PNPB, o Brasil alcançou papel de destaque, no cenário mundial, graças, principalmente, a apresentação de suas vantagens comparativas, especialmente por possuir um amplo território, com clima favorável ao cultivo de grande variedade de matérias-primas, com potencial para a produção de biocombustíveis, bem como um setor de pesquisa agropecuária estruturado.

O governo brasileiro vislumbrou a oportunidade de associar o estímulo a geração de novos negócios, associado à promoção do desenvolvimento rural e a inclusão social dos agricultores familiares.

Nessa condição é importante destacar que houve uma rápida mobilização das empresas produtoras de biodiesel que, mediante as normas estabelecidas, no Programa Selo Combustível Social, passaram a interagir com os agricultores familiares, em diferentes regiões do país.

Cabe, entretanto, avaliar com maior profundidade, quais são os avanços que vêm sendo obtidos e quais os riscos que podem interferir na consolidação do Selo Combustível Social.

Apesar das críticas iniciais, até o presente momento, têm prevalecido as abordagens que consideram como possível a integração das cadeias produtivas de alimentos e energia, articuladas por meio de sistemas de produção agropecuários integrados, sem diminuir a diversificação de culturas que tem sido um das características principais para a sustentabilidade da agricultura familiar no Brasil.

Esse cenário propicia uma análise menos retórica e baseada em dados concretos, como a realizada no presente trabalho.

Segundo Souza Junior (2013), esse desafio “inclui também a viabilização técnica - e de escala de produção - a diversificação das fontes de alimentos e bioenergia, o aumento da produtividade e a redução dos custos de produção - com destaque para a diminuição da dependência de fertilizantes oriundos de fontes não renováveis".

\section{MATERIAL E MÉTODOS}

Para a realização deste trabalho foi escolhida a região centro paulista, nas safras 2010/2011, 2012/2012 e $2012 / 2013$, tendo em vista que uma organização de agricultores familiares, a Cooperativa dos Agricultores Familiares da Região Centro Paulista (COOPERFASC) decidiu, em 2009, produzir oleaginosas, no âmbito do Programa Selo Combustível Social, do Governo Federal.

Desta forma, foi possível acompanhar e avaliar o desempenho dessa iniciativa da Cooperfasc ao longo de 03 safras agrícolas, concomitantemente com as atividades acadêmicas do Curso de Doutoramento em Energia na Agricultura da Faculdade de Ciências Agronômicas da Unesp de Botucatu.

A pesquisa baseou-se na metodologia de estudo de caso e foi realizada nos Assentamentos Fazenda Monte Alegre, gerido pela Fundação Instituto de Terras do Estado de São Paulo - ITESP e Bela Vista do Chibarro que é gerenciado pelo Instituto Nacional de Colonização e Reforma Agrária - INCRA, por serem os locais em que atuam os associados da Cooperfasc.

Nesses 02 Assentamentos Rurais, existem mais de 600 famílias, sendo que existe um relacionamento de colaboração, com as atividades de pesquisa, por parte dos dirigentes das Cooperfasc, desde a sua constituição em 2004.

Cabe destacar que a escolha do Assentamento Fazenda Monte Alegre, que abrange os municípios de Araraquara-SP, Matão-SP e Motuca-SP, foi reforçada pela importância que o Assentamento tem para MotucaSP, antigo Distrito de Araraquara-SP, com apenas 229 $\mathrm{km}^{2}$, sendo que $20 \%$ do seu território corresponde ao Assentamento Fazenda Monte Alegre.

Já quanto ao Assentamento Bela Vista do Chibarro, localizado no Município de Araraquara, trata-se de um dos Assentamentos mais antigos da região, formalizado em 1989, compatível com o período de implantação do Assentamento Fazenda Monte Alegre que ocorreu de 1985 a 1997, permitindo melhores parâmetros para o estudo, abrangendo 02 assentamentos rurais de uma mesma região.

As informações gerais sobre os referidos Assentamentos estão apresentadas na Tabela 1: 
Tabela 1 - Assentamentos acompanhados na pesquisa.

\begin{tabular}{|c|c|c|c|c|c|}
\hline Municipio & Projeto de Assentamento & $\begin{array}{c}\text { Início da } \\
\text { implantação }\end{array}$ & $\begin{array}{c}\text { Domínio da } \\
\text { terra }\end{array}$ & $\mathrm{N}^{\circ}$ de lotes & Área total (ha) \\
\hline Motuca. & Monte Alegre 1 & $05 / 85$ & Estadual & 49 & 726,00 \\
\hline Motuca & Monte Alegre 2 & $10 / 85$ & Estadual & 62 & 857,70 \\
\hline Araraquara & Monte Alegre 3 & $08 / 86$ & Estadual & 76 & $1.099,56$ \\
\hline Motuca & Monte Alegre 4 & $08 / 86$ & Estadual & 49 & 679,35 \\
\hline Araraquara & Bela Vista do Chibano & $12 / 89$ & Federal & 176 & $3.455,16$ \\
\hline Motuca & Monte Alegre ₹ & $10 / 91$ & Estadual & 34 & 483,76 \\
\hline Araraquara & Monte Alegre 6 & $05 / 97$ & Estadual & 88 & $1.253,94$ \\
\hline Total & & & & 534 & $8.555,47$ \\
\hline te. & Dados & Fur & ×̃̃o & ITESP & (2014) \\
\hline
\end{tabular}

Originalmente, o Assentamento Bela Vista do Chibarro possuía 176 lotes, com área de 3455,16 hectares, com lotes variando de 11 a 19 hectares, sendo que, a partir de 2006, o INCRA tem subdividido alguns lotes.

De acordo com as informações levantadas, junto ao ITESP e à Prefeitura Municipal de Motuca, o Assentamento Fazenda Monte Alegre, começou a ser implantado em 1985, em uma antiga propriedade da FEPASA, anteriormente pertencente à Companhia Paulista de Estradas de Ferro, que utilizava a área para a produção de eucalipto, para fabricação de dormentes para as estradas de ferro.

Para melhor compreensão, considerou-se como região centro paulista, a divisão territorial estabelecida pela Secretaria da Agricultura e Abastecimento do Estado de São Paulo, abrangendo 16 municípios, conforme apresentado na Figura 1.

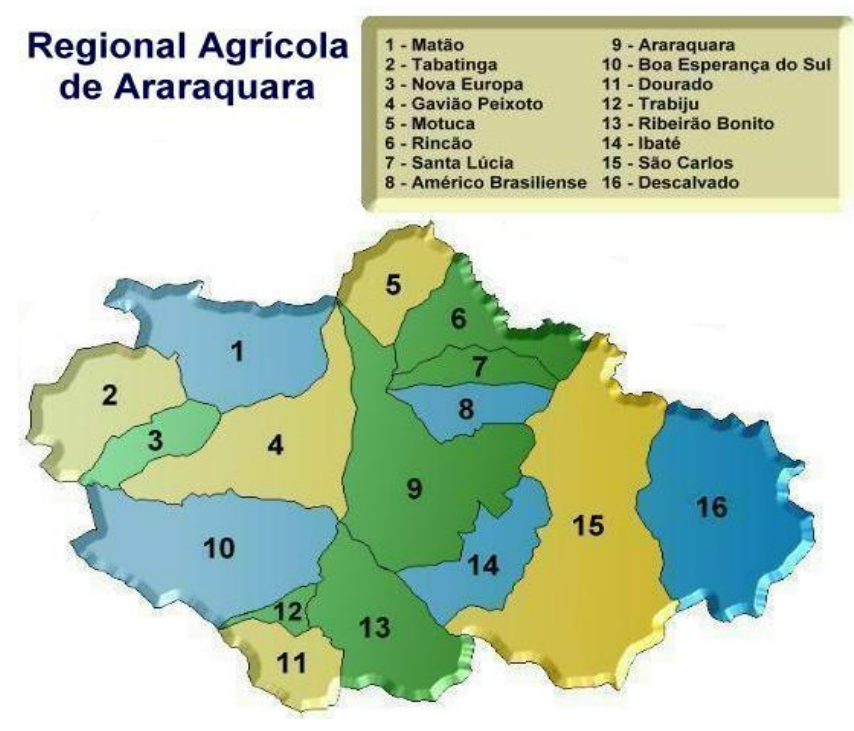

Figura 1 - Região Centro Paulista.

Fonte: CATI (2013).

Para avaliar os riscos e oportunidades do Selo de Combustível Social, na região centro paulista, foi realizado o acompanhamento presencial de 03 safras agrícolas, 2010-2011; 2011-2012 e 2012-2013, junto aos cooperados da Cooperfasc que cultivaram soja, nos Assentamentos Bela Vista do Chibarro e Fazenda Monte Alegre, com a finalidade de fornecer matéria prima para empresas produtoras de biodiesel.

A Cooperfasc fez a opção pela cultura da soja por se tratar da única cultura que as empresas produtoras de biodiesel, atuantes no Estado de São Paulo, dispunhamse a efetivar contratos prévios de fornecimento.

\section{RESULTADOS E DISCUSSÃO}

A Cooperfasc buscou uma parceria com uma empresa de biodiesel da região, que estava em busca da obtenção do Selo Combustível Social, junto ao MDA, que acabou não cumprindo o acordado com os agricultores. Assim, a Cooperativa teve que arcar com todos os custos, dando continuidade ao Arranjo Produtivo Local (APL) de Oleaginosas por conta própria, sendo que os fornecedores de insumos foram informados que só receberiam os pagamentos dos mesmos (sementes, fertilizantes, herbicidas, fungicidas, inseticidas, etc.) após a colheita da soja.

A Figura 2 permite visualizar a complexidade do trabalho desenvolvido em função da logística envolvida, pois o Assentamento Fazenda Monte Alegre é subdividido em 06 áreas, sendo que, apesar de agrupadas, nos Assentamentos I, II, IV e V, onde foram efetuados plantios, essas áreas estão interligadas somente por estradas de terra, sendo que um trator ou colhedora leva mais de 90 minutos para percorrer $9 \mathrm{~km}$ entre o Assentamento II e o Assentamento V. Assentamento Monte Alegre Localização dos lotes do projeto de biodiesel - 2010/2011

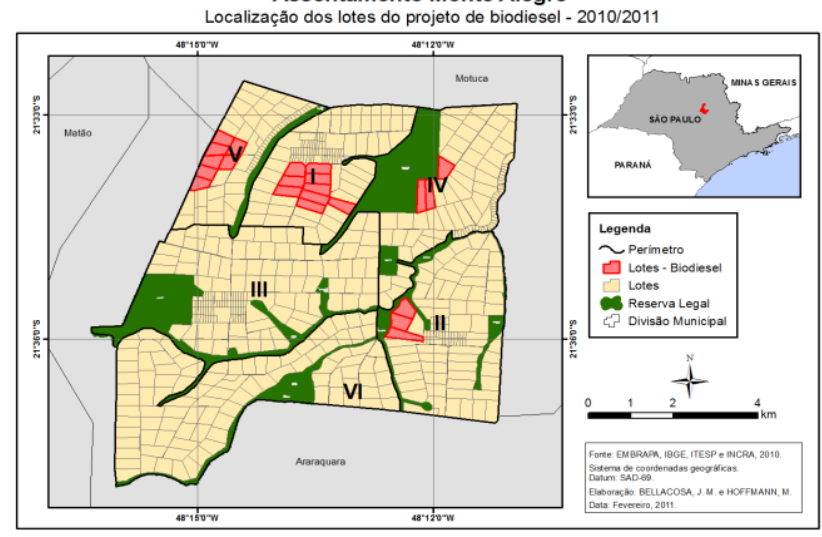

Figura 1 - Levantamento das áreas cultivadas com soja, pela Cooperfasc (fevereiro de 2011).

Fonte: Bellacosa; Hoffmann (2011).

As áreas com destaque na cor rosa, localizadas nos Assentamentos I, II, IV e V, todas pertencentes ao Município de Motuca-SP, representam os lotes que realizaram a produção de soja nessa safra, sendo que foram escolhidos lotes contíguos, visando facilitar as operações agrícolas, reduzindo os custos de produção. Houve grandes dificuldades nessa safra, uma vez que as áreas, disponibilizadas pelos assentados da Fazenda 
Monte Alegre, conforme apresentado por DUTRA, (2013) ou estavam abandonadas, ou possuíam muita "soqueira" de cultivos anteriores de cana-de-açúcar, sendo que a operação de limpeza inicial dos lotes demandou a utilização intensiva de mecanização, aumentando os custos de produção. Na Figura 3 é possível observar a situação da maioria dos lotes que foram destinados ao plantio de soja, no Assentamento Fazenda Monte Alegre, na safra 2010/2011.

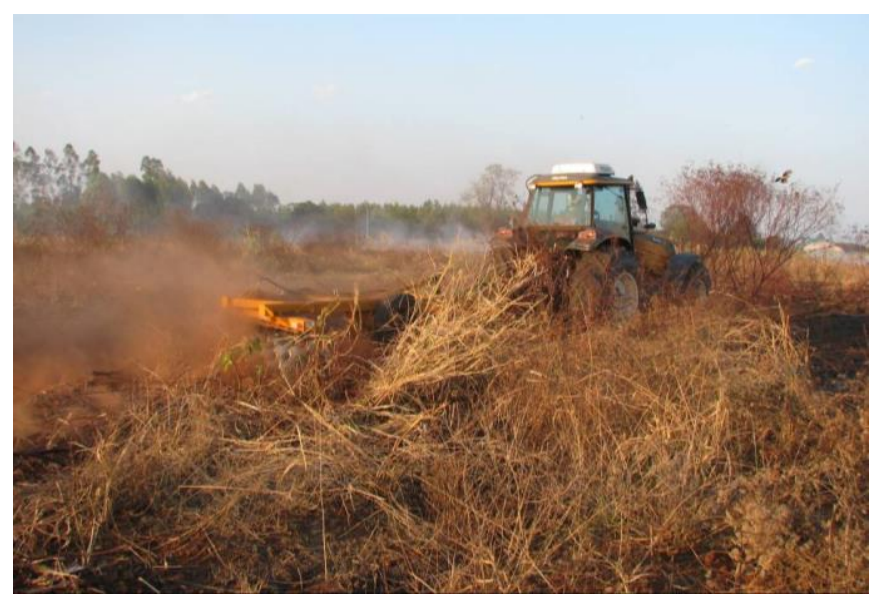

Figura 2 - Preparo de solo no Assentamento I da Fonte: Dutra (2013). Fazenda Monte Alegre.

Embora amplamente discutida, a parceria com a empresa de biodiesel com os assentados da região centro paulista não foi efetivada no tocante aos aportes financeiros previstos.

A empresa inclusive deu entrada na documentação, junto ao MDA, para a obtenção do Selo Combustível Social, que realizou uma vistoria em janeiro de 2011.

Em fevereiro de 2011, após o laudo da vistoria, do MDA, apontar que o APL de oleaginosas, implantado na região centro paulista não abrangia toda a área proposta pela empresa para a obtenção do Selo Combustível Social e que por esse motivo o Selo Social não poderia ser concedido, a empresa rompeu a parceria de forma unilateral, abandonando o projeto.

Como não houve a disponibilização de recursos financeiros para contratação de serviços de máquinas, na área de plantio prevista, originalmente, o cultivo de soja ficou limitado aos lotes que puderam ser preparados e mantidos com máquinas e implementos, disponibilizados pela Prefeitura Municipal de Motuca.

Essa experiência aponta o risco do estabelecimento de contratos com empresas sem comprovada capacidade de pagamento, percepção que, na maior parte das vezes, não está ao alcance dos agricultores familiares e suas organizações.

A produtividade da soja variou bastante, no Assentamento Fazenda Monte Alegre, sendo a média de 21,03 sacos de soja, por hectare, sem considerar os 02 lotes não colhidos, em função da infestação com mucuna preta (Mucuna aterrima). O número de lotes plantados foi limitado em função da dissolução da parceria com a empresa de biodiesel. A produtividade pode ser considerada regular levando em conta o tipo de solo e a fertilidade de cada lote, tendo em vista os dados apresentados por Medeiros e Leite (2004). Os solos, no Assentamento Bela Vista do Chibarro, apresentam condições de fertilidade superiores, em relação à Fazenda Monte Alegre. Entretanto, devido às dificuldades enfrentadas, por parte da Cooperfasc, em todo o processo, somente 03 lotes foram plantados com soja, no Assentamento Bela Vista do Chibarro, na safra 2010/2011, atingindo a média de 36,25 sc./ha comprovando o potencial produtivo desse Assentamento, que balizou a decisão da Cooperativa de ampliar os plantios, na safra 2011/2012.

Os resultados de produção e produtividade, em cada lote, estão representados nas Figuras 4 e 5.

O MDA foi informado da situação, por parte da Cooperativa, e comprometeu-se a apoiar a Cooperfasc para que estabelecesse parceria com uma empresa detentora do Selo Combustível Social, para a continuidade dos plantios na próxima safra.

Nos meses de maio e junho de 2011, foram realizadas reuniões entre a Cooperfasc e cinco diferentes empresas de biodiesel, atuantes no Estado de São Paulo. Somente em setembro de 2011 foi formalizada a parceria da Cooperfasc, com uma dessas empresas, sendo que a partir dessa data foram definidas as áreas para plantio nos Assentamentos Bela Vista do Chibarro e Fazenda Monte Alegre.

No Assentamento Fazenda Monte Alegre ocorreu uma intervenção do ITESP que, alegando não cumprimento da Portaria 077/2004, que limita a utilização de no máximo $50 \%$ dos lotes para a produção destinada a agroindústrias, impediu que os cooperados desse assentamento plantassem toda a área do lote com soja, na safra 2011/2012.

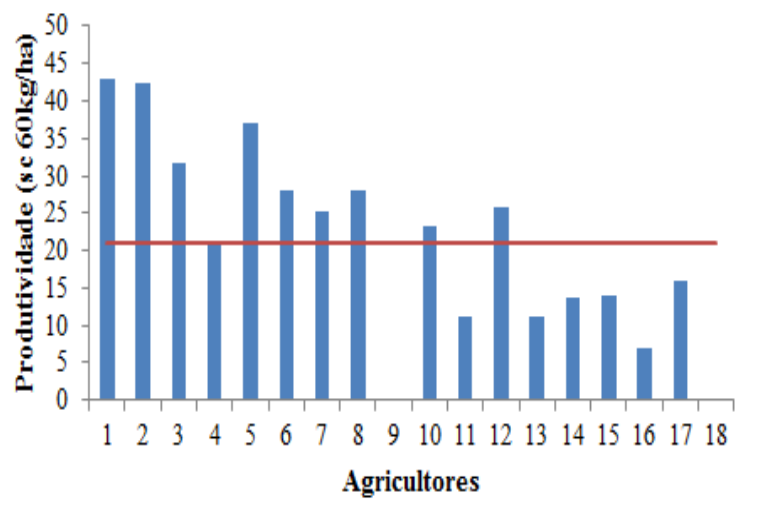

Figura 3 - Safra 2010/2011 - produtividade média de sojapor hectare no Assentamento Fazenda Monte Alegre.

Fonte: Dutra (2013). 


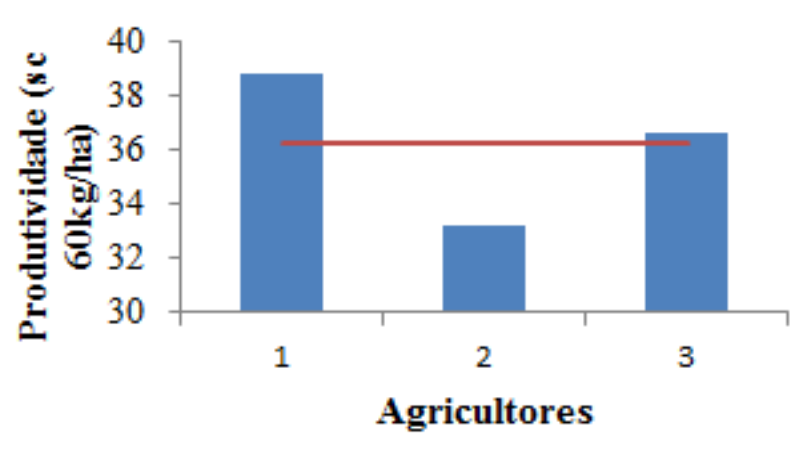

Figura 4 - Safra 2010/2011 - produtividade média de soja por hectare no Assentamento Bela Vista do Chibarro.

Fonte: Dutra (2013).

Esse acontecimento, formalizado por notificações do ITESP, em dezembro de 2013, reduziu a previsão de área a ser plantada no Assentamento Fazenda Monte Alegre em $50 \%$, sendo que não houve tempo hábil para ampliar a área a ser plantada no Assentamento Bela Vista do Chibarro.

A Cooperfasc protocolou recurso, junto ao ITESP, solicitando a autorização para continuidade do plantio de soja para indústrias de biodiesel, dando a família dos assentados oportunidade de se integrarem ao setor produtivo da agricultura, cumprindo a função social da terra pública que lhes fora cedida, produzindo para seu sustento, sendo que toda a documentação está arquivada na sede da Cooperfasc, em Motuca-SP.

A Cooperativa argumentou que o plantio de soja, em todo o lote, nas condições em que estava sendo feito, era interessante, pois em um ciclo de menos de 05 meses, propiciaria a fixação biológica de nitrogênio, bem como esclareceu, que de acordo com o projeto de plantio, estavam sendo aplicados corretivos de solo, como calcário dolomítico e gesso agrícola.

Foi destacado, naquela ocasião, que o plantio de metade da área dos lotes, implicaria em maior custo por unidade de área, sem que se dispusesse, naquele momento, de uma melhor opção, em termos de rentabilidade para o plantio na outra metade do lote.

Entretanto, os responsáveis pelo escritório regional do ITESP de Araraquara, mantiveram-se irredutíveis, ao ponto que um assentado, do Assentamento $\mathrm{V}$ da Fazenda Monte Alegre, chegou a gradear uma área com soja estabelecida, com cerca de 60 dias que excedia aos $50 \%$ do lote autorizados pelo ITESP.

O MDA foi informado da situação, mas não houve tempo hábil para reverter o quadro, que juntamente com os "veranicos"*, ocorridos em fevereiro e março de 2012, reduziram em cerca de $30 \%$ a produção no Assentamento Fazenda Monte Alegre. Os resultados de produção e produtividade desta safra estão representados nas Figuras 6 e 7.

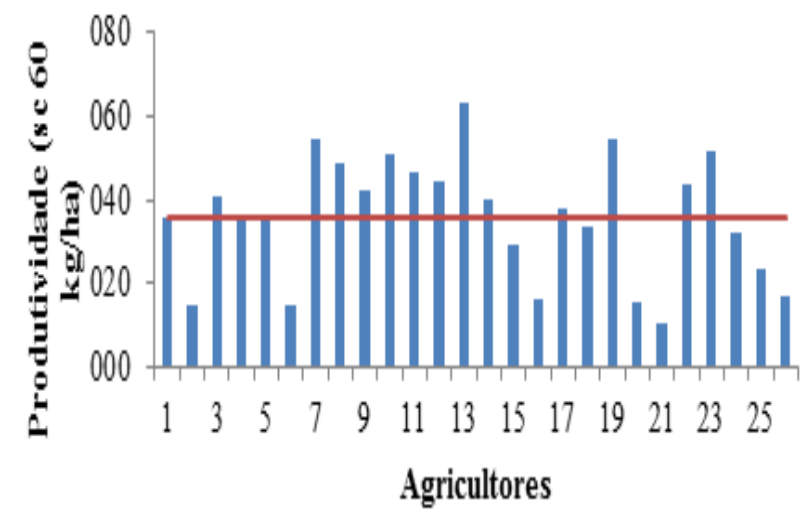

Figura 6 - Safra 2011/2012 - Produtividade média de soja por hectare no Assentamento Fazenda Monte Alegre.

Fonte: Dutra (2013).

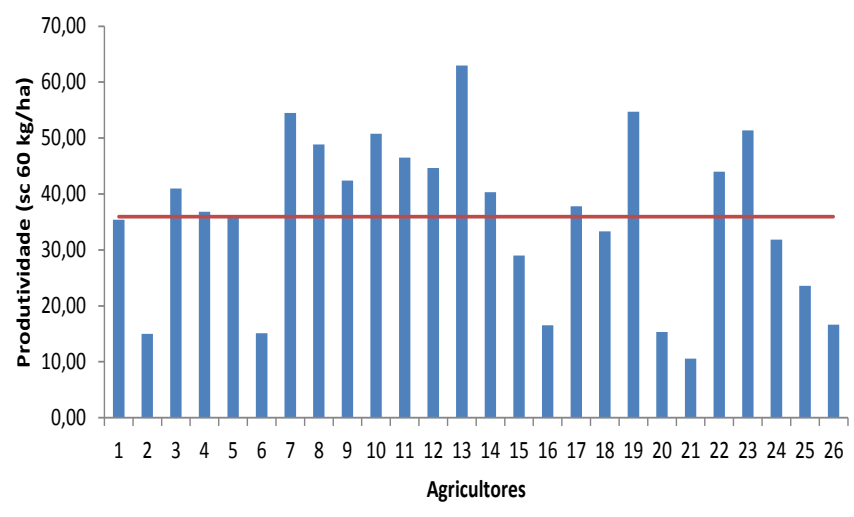

Figura 7 - Safra 2011/2012 - Produtividade média de soja por hectare no Assentamento Bela Vista do Chibarro.

Fonte: Dutra (2013).

A produtividade média, de acordo com Dutra (2013) foi de $18,94 \mathrm{sc}$. de soja por hectare no Assentamento Fazenda Monte Alegre e de 35,97 sc. de soja por hectare no Assentamento Bela Vista do Chibarro.

Tendo em vista que o custo de produção foi de, aproximadamente, 22 sacos de soja de $60 \mathrm{~kg}$, por hectare, cerca de $52 \%$ dos agricultores não conseguiram cobrir os custos de produção. Desta forma, o resultado econômico final dessa safra implicou em uma dívida da Cooperfasc, junto à empresa de biodiesel parceira, em torno de $\mathrm{R} \$ 70.000,00$ (setenta mil reais).

Neste aspecto é importante destacar que o Programa Selo de Combustível Social, até aquela data, não previa nenhum tipo de seguro, ou de instrumento para que os agricultores familiares e suas organizações pudessem amenizar suas perdas com a frustração da safra, em função da seca.

Nas Figuras 8 e 9 apresentam-se os dados referentes à produção e produtividade nos Assentamentos Bela Vista do Chibarro e Fazenda Monte Alegre, na safra 2012/2013. 
A safra 2012-2013 apontou uma diferença significativa de produtividade entre as áreas que já haviam sido plantadas com soja, nas safras anteriores, com as novas áreas, plantadas pela primeira vez nessa safra.

No Assentamento Bela Vista do Chibarro a produtividade média foi de 33,00 sc. de soja por hectare. Já no Assentamento Fazenda Monte Alegre a produtividade média foi de 27,80 sc. de soja por hectare.

O principal fator para essa significativa variação de produtividade entre os lotes foi o tipo de manejo de solo, uma vez que nas áreas cultivadas anteriormente com soja, foi realizado plantio direto, enquanto que nas áreas novas foi necessário efetuar correção de solo, incorporação do corretivo, bem como utilizar grade niveladora, gerando um custo maior, sem que houvesse um retorno desses investimentos na safra 2012-2013.

Em síntese, até a véspera da semeadura da safra 2012/2013, vigorava a Instrução Normativa $n^{\circ} .1$, de 19 de fevereiro de 2009, que dispõe sobre os critérios e procedimentos relativos à concessão, manutenção e uso do selo combustível social, que era o instrumento legal em vigência, ao longo de quase todo o período em que foi realizada a pesquisa, e que estabelecia três eixos principais a serem cumpridos por parte das empresas produtoras de biodiesel:

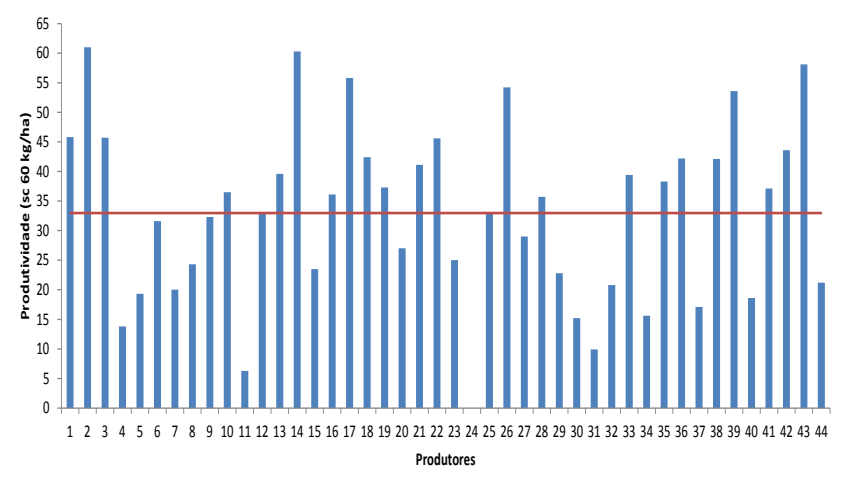

Figura 8 - Safra 2012/2013 - produtividade média de soja por hectare no Assentamento Bela Vista do Chibarro.

Fonte: Dutra (2013).

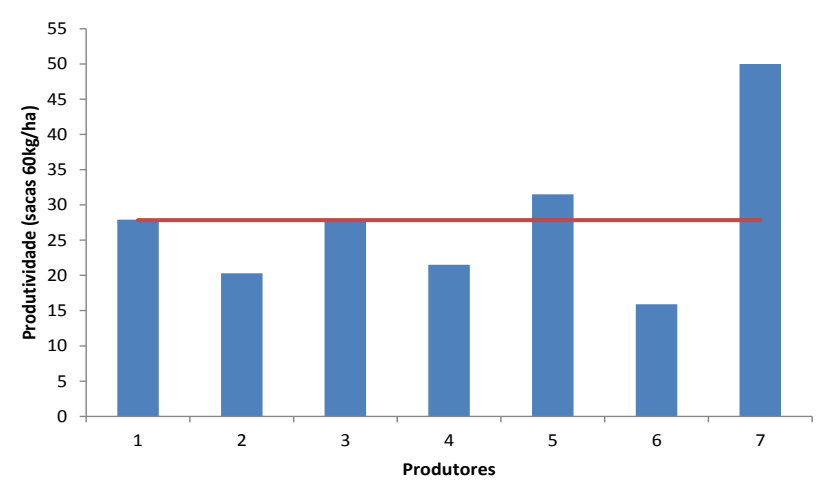

Figura 9 - Safra 2012/2013 - produtividade média de soja por hectare no Assentamento Fazenda Monte Alegre.

Fonte: Dutra (2013). a) adquirir de agricultor familiar matéria-prima para a produção de biodiesel em uma quantidade mínima definida pelo MDA.

Com relação a este item, apesar do Programa Selo Combustível Social estabelecer uma ponderação maior para as matérias-primas que não sejam a soja, na prática não há muitas opções com domínio tecnológico e rentabilidade que possam dar segurança para os agricultores familiares, especialmente os assentados da reforma agrária;

b) celebrar contratos com os agricultores familiares, negociados com a participação de uma representação dos agricultores familiares, especificando as condições comerciais que garantam renda e prazos compatíveis com a atividade $\mathrm{e}$

c) assegurar assistência e capacitação técnica aos agricultores familiares.

Com relação aos contratos, os mesmos têm sido objeto de grande preocupação por parte do MDA, entretanto, no caso da cultura da soja, apesar das cláusulas discorrerem sobre "valor de mercado", os preços mínimos vigentes estavam abaixo desse valor, sendo que o fechamento do valor no contrato deveria ter sido efetuado até 31/12 do ano em que a soja foi plantada, conforme estabelece a Portaria 60, de setembro de 2012, do MDA.

A prestação dos serviços de assistência técnica aos agricultores familiares e de sua capacitação para a produção de oleaginosas deve ser desenvolvida diretamente pela equipe técnica do produtor de biodiesel ou por instituições/cooperativas/empresas por ele contratadas ou conveniadas.

Entretanto, na prática as empresas de biodiesel têm muito mais condições de avaliar os cenários futuros e as sinalizações do mercado do que os agricultores familiares.

Nas 03 safras, em que foi realizada a pesquisa, os valores obtidos pela Cooperfasc foram inferiores a média recebida, pelos produtores de soja tradicionais, da região centro paulista. Os autores só tiveram acesso às notas fiscais das remessas de soja pagas pelas empresas de biodiesel à Cooperfasc, mas visitando produtores da região foi possível identificar que os fornecedores tradicionais, das mesmas empresas, receberam em média de $\mathrm{R} \$ 2,00$ a $\mathrm{R} \$ 3,00$, a maior, por saca de soja de $60 \mathrm{~kg}$.

A instrução também prevê que cada técnico poderá responsabilizar-se pelo atendimento, máximo, de 150 (cento e cinquenta) agricultores familiares.

Sem dúvida esse é um dos aspectos mais importantes do Programa Selo Combustível Social, qual seja a garantia de assistência técnica, entretanto, apesar desse custo estar incluído na contabilização que as empresas produtoras de biodiesel fazem em relação às compras de matérias-primas da agricultura familiar, a Cooperfasc realizou esse trabalho nas 03 safras acompanhadas, sendo que os valores disponibilizados pela empresa 
foram muito exíguos, o que é limitante para a prestação de um serviço de qualidade.

Na safra 2012-2013, a Cooperfasc concentrou seus esforços na redução dos custos de produção e na intensificação das atividades de assistência técnica.

A quantificação, de 01 técnico para até 150 agricultores, após o acompanhamento de 03 safras, pode ser considerada insuficiente, principalmente se as áreas a serem acompanhadas não estiverem num raio em torno de 30 a $40 \mathrm{~km}$, pois o tempo e o custo despendidos com o deslocamento pode se tornar limitantes às ações de assistência técnica e extensão rural.

Nesta última safra, para prestar um atendimento adequado, a equipe de assistência técnica atuou, em média, de 6 a 7 dias por semana, das 6:30 às 21:00 h.

Em setembro de 2012, o MDA publicou a Portaria 60, que ampliou e detalhou a regulamentação do Programa Selo Combustível Social.

A seguir, foi efetuado um destaque de alguns trechos, considerados relevantes, da referida Portaria, para a presente pesquisa.

\section{Art. 3}

$\boldsymbol{I V}$ - valor referente a contratos, convênios, termos de parceria, ou outros instrumentos previstos em lei realizados com órgãos oficiais de pesquisa para pesquisas agropecuárias relacionadas à diversificação de matérias-primas produzidas pela agricultura familiar;

Essa iniciativa é bastante válida, entretanto as empresas querem resultados em um curto espaço de tempo e mesmo em culturas conhecidas e produzidas comercialmente, um novo cultivar leva no mínimo 05 anos, entre a sua validação e estabilização do ponto de vista do melhoramento genético até a sua disponibilidade para o mercado.

Restringe, também, o aporte de recursos financeiros somente aos órgãos de pesquisa que forem considerados "oficiais", na verdade a intenção pode ter sido valorizar a pesquisa pública, mas, entidades privadas, com competência para assistência técnica e difusão de tecnologia, não podem receber recursos, de empresas produtoras de biodiesel, em função do recorte delimitado pela Portaria.

Art. $6^{\circ}$ No caso de frustração de safra da agricultura familiar, devidamente comprovada, será considerada para fins de cálculo de percentual mínimo de aquisições, a expectativa de produção baseada na área contratada da agricultura familiar e nos coeficientes técnicos de produtividade da cultura por meio do emprego dos dados oficiais, segundo ordem decrescente de escolha, da Companhia Nacional de Abastecimento - Conab, do Instituto Brasileiro de Geografia e Estatística - IBGE, ou de outro órgão público de competência reconhecida para definir a expectativa de produtividade nos seguintes referenciais:

a) na região de produção; e

b) na área mais próxima, caso a região de produção não disponha dos dados necessários.

$\S 1^{o}$ Para aceitação da frustração de safra da agricultura familiar, o produtor de biodiesel deve encaminhar solicitação formal ao MDA, com toda documentação comprobatória da frustração, incluindo minimamente relatórios de acompanhamento de safra da Conab, declarações assinadas por órgãos públicos de assistência técnica e extensão rural no estado, declarações de perdas assinadas por cooperativas agropecuárias contratadas, e quando for o caso, decretos de situação de emergência e calamidade pública do local de frustração.

$\S 2^{\circ}$ A produção esperada neste artigo devido a eventos de frustração de safra será multiplicada pelos fatores previstos no $\$ 7^{\circ}$ do art. $4^{o}$.

Neste caso pode-se considerar um avanço importante, pois anteriormente não havia nenhum mecanismo para amenizar perdas, em função de uma eventual frustração de safra, o que ocorreu na safra 2011-2012, principalmente no Assentamento Fazenda Monte Alegre, conforme relatado, anteriormente.

Art. 15. O produtor de biodiesel poderá assegurar assistência técnica e capacitação de forma permanente ao longo do ano para todas as outras culturas $e$ atividades produzidas nos estabelecimentos dos agricultores familiares contratados para fornecimento de matéria-prima;

Parágrafo único. $O$ valor da assistência técnica $e$ capacitação permanente e para outras culturas $e$ atividades dos estabelecimentos da agricultura familiar, será considerado para fins de cálculo do percentual mínimo de aquisições da agricultura familiar de que trata o art. $3^{\circ}$, respeitando o art. $4^{\circ}$, inciso $V$.

Trata-se, também, de um avanço significativo, uma vez que vislumbra a evolução do agricultor familiar e sua propriedade, não restringindo a assistência técnica ao período específico, ou a área de sua lavoura, dedicada, exclusivamente, ao cultivo de oleaginosas para a produção de biodiesel.

\section{CONCLUSÃO}

O primeiro fator que deve ser considerado é que o Programa Selo Combustível Social é uma política pública que está vinculada ao Plano Nacional de Produção e Uso de Biodiesel - PNPB, lançados sob uma perspectiva estratégica de apresentar uma opção ao processo de esgotamento dos combustíveis fósseis.

Esse contexto estimulou a realização de plantios, quase que exclusivamente de soja, na região centro sul, por 
parte dos agricultores familiares, sendo a experiência da Cooperfasc, na região centro paulista, uma iniciativa originada, de uma expectativa voltada para desenvolver uma nova atividade econômica para os Assentamentos Fazenda Monte Alegre e Bela Vista do Chibarro.

Embora nas 03 safras acompanhadas tenham ocorrido problemas climáticos, bem como uma heterogeneidade elevada no desempenho produtivo dos diferentes agricultores envolvidos, essa iniciativa contribuiu para o aperfeiçoamento dos conhecimentos técnicos de todos envolvidos, tanto por parte dos assentados rurais, como da equipe técnica da Cooperfasc e os técnicos da empresa de biodiesel no que tange aos aspectos práticos da produção de soja em assentamentos rurais.

Outro aspecto positivo foi o fortalecimento da Cooperfasc que está dando continuidade às suas atividades, na safra 2013/2014, por meio do plantio de sementes certificadas, já tendo inclusive obtido o registro no Registro Nacional de Sementes e Mudas (RENASEM), junto ao Ministério da Agricultura, Pecuária e Abastecimento (MAPA).

Nos moldes em que o Programa Selo Combustível Social está estabelecido, o desafio para assentados rurais, sem experiência na produção de soja, é complexo e expõe esses agricultores a riscos, pois as empresas produtoras de biodiesel acabam tendo maior interesse e facilidade para interagir com agricultores e cooperativas que, independentemente do Programa, já se dedicavam à produção dessa oleaginosa.

Destaca-se que, apesar das dificuldades enfrentadas, as lideranças da Cooperfasc, bem como sua equipe técnica, acabaram adquirindo um cabedal de conhecimentos e experiências que estão contribuindo para o fortalecimento de sua organização.

Somente na Instrução Normativa, mais recente, do MDA, de 06 de setembro de 2012, passou a ser autorizada a assistência técnica em outras culturas que não fossem oleaginosas, para a produção de biodiesel. Se este fato tivesse ocorrido desde a safra 2010/2011, os agricultores familiares da região centro paulista, que participaram da constituição desse APL, poderiam ter sido muito mais beneficiados

Conclui-se que, passados quase dez anos do lançamento do PNPB, pairam muitas incertezas quanto ao real interesse governamental em aprimorar e consolidar a iniciativa. Dois fatores podem ser apontados como principais limitadores: pouca diversidade de opções de matérias primas para a produção de óleo vegetal e a falta de uma atuação mais consistente e continuada de apoio às organizações dos agricultores familiares credenciadas pelo Ministério do Desenvolvimento Agrário, para a produção de oleaginosas para a fabricação de biodiesel. Desta forma a falta de sustentabilidade na produção de soja para fornecimento a empresas de biodiesel, nas safras acompanhadas, foi determinante na percepção dos dirigentes e associados da Cooperfasc optarem por direcionar os esforços da organização para outras atividades, a partir da safra 2013/2014.

\section{REFERENCIAS}

ANP - Agência Nacional de Petróleo, Gás Natural e Biocombustíveis. Produção de biodiesel - B100 por produtor - 2005-2014 (m3). Brasília, 2014. Disponível em: 〈www.anp.gov.br/?dw=8740 > . Acesso em: 08 jan. 2014.

BELLACOSA, J.M.; HOFFMANN, M. O cerco dos canaviais: contradições e conflitos nos assentamentos rurais. Agrária, São Paulo, n. 13, pp. 111-136, 2011.

BRASIL.Ministério do Desenvolvimento Agrário. O Selo Combustível Social. Brasília, 2014. Disponível em:

<http://portal.mda.gov.br/portal/saf/programas/biodiesel/ 2286313>. Acesso em 20 abril 2014.

CATI- Coordenadoria de Assistência Técnica Integral. Regional Agrícola de Araraquara. Campinais, 2014 Disponível em

$:\langle$ http://www.cati.sp.gov.br/new/index.php $>$. Acesso em: 15 mai. 2013.

D'ERCOLE, R. De 67 usinas de biodiesel, 27 suspendem produção. O GLOBO, Rio de Janeiro, 17 fev 2014. Disponível em: http://www.biodieselbr.com/noticias/regulacao/r/67usinas-biodiesel-27-suspendem-producao-170214.htm. Acesso em: 18 abril 2014.

DUTRA, S.G. Impactos e perspectivas do selo de combustível social em assentamentos rurais da Região Centro Paulista. 2013. 126f. Tese (Doutorado em Agronomia/Energia na Agricultura). Faculdade de Ciências Agronômicas-Universidade Estadual Paulista. Botucatu, 2013.

IEA - Instituto de Economia Agrícola. Preços Médios Mensais Recebidos pelos Agricultores - Soja. Campinas, 2014. Disponível em: <http://ciagri.iea.sp.gov.br/nia1/precos_medios.aspx? cod_sis=2 >. Acesso em: 08 jan. 2014.

ITESP - Fundação Instituto de Terras do Estado de São Paulo. Situação Quanto à Localização Municipal. São Paulo, 2007. Disponível em <

http://www.itesp.sp.gov.br/br/info/acoes/assentamentos.a spx >. Acesso em: 08 jan. 2014.

GRAZIANO DA SILVA. Política para o setor sucroalcooleiro frente à crise: uma proposta alternativa para o Estado de São Paulo. São Paulo, 2000. Disponível em:

<http://www.lula.org.br/assets/politica_setor_sucroalcoo leiro.pdf >. Acesso em 20 mar. 2013.

MEDEIROS, L.S.; LEITE, S. Assentamentos Rurais: Mudança Social e Dinâmica Regional. Rio de Janeiro: Mauad, 2004. 305p. 
NOVACANA. A evolução da produtividade da canade-açúcar. Curitiba, 2014. Disponível

em:<http://www.novacana.com/estudos/a-evolucao-daprodutividade-da-cana-de-acucar-160813/\#. Acesso em: 20 abril 2014.

PORTAL BRASIL. Produção de biodiesel gerou mais de R\$ 2 bi para agricultura familiar. Brasília, 2014.

Disponível em:

http://www.brasil.gov.br/infraestrutura/2013/03/produca o-de-biodiesel-gerou-mais-de-r-2-bi-para-agriculturafamiliar. Acesso em: 18 abril 2014.

SARMENTO, P.H.L. Viabilidade econômica da produção de biodiesel na região sudeste de Mato Grosso. 2010. 118f. Dissertação (Mestrado em Economia Aplicada). Escola Superior de Agricultura Luiz de Queiroz- Universidade de São Paulo. Piracicaba, 2010.

SOUZA JUNIOR, M. T. Desafios da produção de alimentos e bioenergia no Brasil. Jornal

Agroenergético n. 42, Embrapa, p. 10-11, jun. Brasília, 2013. Disponível em:

<http://www.cnpae.embrapa.br/imprensa/jornalagroenergetico/Agroenergetico_42.pdf/view.> Acesso em 15 fev. 2014. 